Article

\title{
A Game Theoretic Approach for Improving Environmental and Economic Performance in a Dual-Channel Green Supply Chain
}

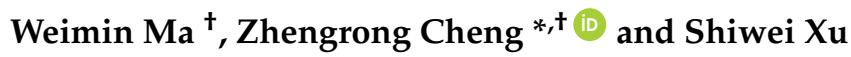 \\ School of Economics and Management, Tongji University, Shanghai 200092, China; mawm@tongji.edu.cn (W.M.); \\ swxu1228@163.com (S.X.) \\ * Correspondence: 110 czr110@163.com \\ + These authors contributed equally to this work.
}

Received: 15 May 2018; Accepted: 3 June 2018; Published: 8 June 2018

\begin{abstract}
In this paper, we investigate economic performance and environmental performance of a dual-channel green supply chain (GSC). Given that most relevant literature still focus on the descriptive aspect of GSC, we adopt game theoretic approach rather than qualitative analysis method to address the following problems: (1) How can the integration of environmental and economic sustainability goals be achieved in GSC? (2) What is the impact of customer environmental awareness on the green level and profitability of the GSC? (3) How does the market demand changes in the presence of the online direct channel in addition to the traditional one? We establish four game models, which are decentralized scenario, centralized scenario, retailer-led revenue-sharing scenario and bargaining revenue-sharing scenario. In the decentralized scenario, participants in a GSC make individual decisions based on their specific interests. In the centralized scenario, the GSC is regarded as a whole and the participants make collective decisions to maximize the overall profit of the GSC. In addition, in the two revenue-sharing scenarios, revenue-sharing contracts as the important profit coordination systems are set up and the revenue-sharing ratio is determined either by the retailer or through bargaining. Moreover, the cost of green product research and development, customer environmental awareness and price sensitivity are also taken into account in the four scenarios. By comparing and analyzing the four game models, we recommend the two revenue-sharing scenarios as the optimum choice and improving green awareness as a feasible strategy to achieve the integration of economic and environmental goals of the GSC. Additionally, we find that online sales has become a major distribution channel of the GSC.
\end{abstract}

Keywords: sustainability; green supply chain; green degree; game model

\section{Introduction}

Human activities have to a large extent changed the functioning of the planetary systems [1]. In order to curb the ecological deterioration, sustainable development strategy should be implemented [2]. With regard to corporate sustainability, the lens is beginning to be widened from a specific company to the entire supply chain (SC) [3]. In addition, the impact on environment as well as resource use efficiency need to be considered at the level of supply chain management (SCM) rather than within the boundary of a company [4]. Consequently, the concept of green supply chain (GSC) was proposed and has gained rapidly growing attention from both academia and industry [5].

In contrast to traditional SCM, which typically focuses on economic performance, green supply chain management (GSCM) aims at the integration of environmental and economic sustainability [6]. However, there is still conflicting viewpoints on whether such integrated goals could be achieved [7]. 
Some researchers claim that the environmental improvement does not always lead to profitability and sometimes may conflict with the economic goal [8]. On the other hand, some researchers argue that GSCM practices may improve a company's economic performance [9]. These indicate that advancing the green level of the GSC has both negative and positive impacts on economic performance [10]. Nevertheless, turning a blind eye to environmental issues is no longer an option for a company, and GSCM is thus an indispensable requirement [11].

Moreover, customer purchasing behavior has become an important factor affecting the GSCM implementation with the tremendous increase of global consumption [12]. Many investigations indicate that more customers than ever have shown their environmental concerns and desires to purchase green products [13]. However, there is a gap between consumers' positive attitudes and actual actions, and green consciousness does not always lead to green purchasing behavior [14]. In addition, rapid development of the Internet has significantly changed customer purchasing behavior and the structure of GSC distribution [15]. The rise of online shopping prompts manufacturers to adopt dual-channel strategy, which may expand market share, reduce costs and increase profits [16].

Motivated by everything mentioned above, we investigate the alignment issues between environmental and economic performance of GSC. Previous research mainly focused on description, case study, survey and other empirical methods. In this paper, we adopt game theoretic approach rather than qualitative analysis to answer the following questions:

(1) How can the integration of environmental and economic sustainability goals be achieved in GSCM?

(2) What is the impact of customer environmental awareness on the green level and the profitability of the GSC?

(3) How does the market demand change in the presence of the online direct channel in addition to the traditional one?

In the process of problem-solving, we establish four game models based on a dual-distribution GSC: (i) decentralized scenario where the manufacturer and the retailer of the GSC make decisions independently based on their own interests; (ii) centralized scenario where the GSC is treated as a whole and the manufacturer and the retailer make collective decisions to maximize the overall profit of the GSC; (iii) retailer-led revenue-sharing scenario where the profit coordination mechanisms are set up and the retailer determines the revenue-sharing ratio; (iv) bargaining revenue-sharing scenario where the manufacturer and the retailer determine the revenue-sharing ratio through bargaining in the profit coordination mechanisms. Moreover, the cost of green product research and development $(R \& D)$, customer environmental awareness and price sensitivity are also taken into account in the four scenarios.

The main contributions of this paper are presented as follows. First, a game theoretic approach is adopted, and the equilibrium solutions are calculated in four different scenarios. Second, environmental and economic performances in the four scenarios are compared and analyzed to help make decisions in GSCM practice. Third, we assume that the manufacturer can sell green products to customers through both the online direct channel and the traditional channel. Finally, factors such as green product R\&D cost, customer green sensitivity and price sensitivity, which affect the green level and profitability of GSCM, are taken into account.

The rest of the paper is organized into six sections. In Section 2, a brief review of relevant literature is provided. In Section 3, the problem structure is described and four game models are introduced. In Section 4, the optimal solutions of the four scenarios are acquired. In Section 5, the four game models are compared and analyzed. Section 6 provides a numerical example to illustrate the sensitivity of the optimal solutions to some parameters. Finally, conclusions and future research directions are outlined in Section 7. 


\section{Literature Review}

$\mathrm{SC}$ is a vertical sequence of independent transactions, which can be viewed as a flow of material, products and information and a set of corporate activities [17]. It is not surprising that corporate sustainable strategies have been extended through the SC for the broader adoption and development of sustainability [3]. GSCM is an effective management tool and philosophy to embed environmental sustainability into SCM [18]. In addition, many activities are involved in GSCM, such as green product design, materials acquisition, green manufacturing processes, distribution, use, and resource recycling [19]. However, the scope of GSCM in the literature has varied according to the goal of the investigator [20]. In this paper, we shall focus on the manufacturer-retailer-customer relationship and pertinent activities of green production, green marketing and green purchasing in the dual-channel structure.

Environmental and economic performances of GSM have been a topic of intense interest in GSCM literature, where both positive and negative relations between the two performances are observed. As for research methods, survey research and case study are dominant and thus most relevant literature still concentrate on the qualitative aspect of GSCM [21]. In addition, many of the related studies are criticized for lacking in long term results and helping make decisions in GSCM [22]. In this paper, we use quantitative analysis method and provide insights on the effects of factors such as green production, sale channel and green customer on the green level and profitability of GSCM.

Given that better planning and coordination of GSCM practices can generate positive environmental and economic effects, some researchers developed mathematical models to assess the impacts of decision-making and operation of GSC players [23]. Moreover, corporate approaches for performance improvement cannot be undertaken in isolation, so a concerted effort along GSC players is needed [24]. On the other hand, with different profit targets and operation strategies, GSC players can hardly maintain consistency on everything, and sometimes they are in competition with one another. Among all the mathematical methods used in GSCM literature, game theory is highly applicable to the research on the coexistence of competition and cooperation among GSC players.

In the field of GSC logistics, game theory is applied not only to forward logistics but also to reverse logistics whose function are recycling, reusing, and remanufacturing. As a forward logistics example, Barari et al. [25] studied the coordination between the manufacturer and the retailer in an evolutionary game model. They found such coordination could increase environmental benefits and commercial advantages of GSC. As a reverse logistics example, Sheu and Chen [26] applied a three-stage game model to a GSC with both forward and reverse logistics. In addition, low-wholesale-price strategies are suggested for recycling processes under government green subsidization. In this paper, our scope covers only forward logistics of GSC.

We categorize the coexistence of competition and cooperation of GSC players into types of chain and chain, channel and channel, upstream and downstream companies. Jamali and Rasti-Barzoki [12] studied the chain-chain competition of two dual-channel SCs under centralized and decentralized scenarios. They found that the centralized scenario achieves a higher green level of production than the decentralized one does. Chen et al. [27] investigated duopoly GSC with upstream-downstream and channel-channel competition. They explored how manufacturers' market power influences the pricing policies and green strategies. Ghosh and Shah [28] explored the effect of decentralized policy and cooperative policy on the green level of products in a secondary SC composed of a manufacturer and a retailer. The green level is decided individually by the manufacturer in the decentralized policy, while cooperative decisions are made between the upstream and downstream players in the cooperative policy. Then they further put forward a contractual coordination mechanism. In this paper, we focus on the competition and cooperation of channel-channel and upstream-downstream types.

There are many application aspects of game theory to GSCM, such as R\&D collaboration, governmental intervention and pricing policy. Dai et al. [29] established Stackleberg game models to study R\&D collaboration between GSC members. They revealed that the upstream company generally prefers a Cartelization, while the downstream company mostly favors a non-cooperative scheme. In addition, the Cost-sharing contract generally makes the chain-wide profit get to the summit. Yang and Xiao [30] 
used game method to explore the governmental interventions in a GSC. They found that with the increase of governmental interventions, the green level of GSC will increase. However, a relatively high green level floor for subsidy causes the first-mover disadvantage of manufacturers. Wei et al. [31] studied the pricing problem in the GSC comprised of two manufacturers and one retailer. In view of the manufacturers' cooperation or noncooperation strategies, they adopted the centralized models and decentralized models. In this paper, we regard prices as decision variables in our game models.

\section{Problem Statement and Formulation}

\subsection{Problem Description}

In this paper, we investigate the alignment issues between green level and economic performance of GSC. We are particularly interested to see how the alignment may be achieved through competition and cooperation of the GSC participants. To answer this question, we take into account a dual-distribution GSC composed of a manufacturer, a retailer and customers, as shown in Figure 1. The manufacturer produces green products, which are sold to customers through a retailer or a direct channel. Based on this, four game models are established. Moreover, the effects of green product R\&D cost, customer green sensitivity and price sensitivity, are evaluated into the above models by using corresponding coefficients.

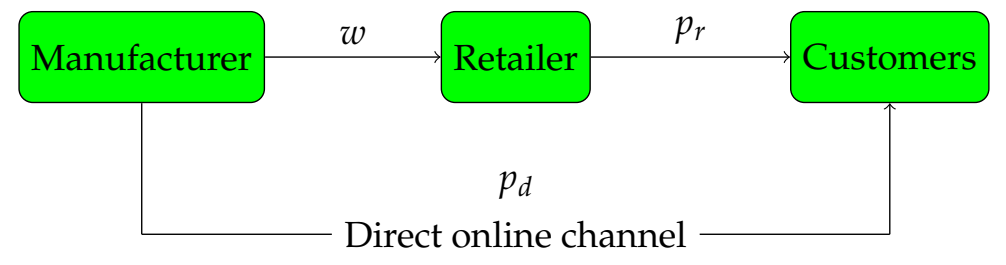

Figure 1. Problem structure.

\subsection{Notation}

We collect model parameters and decision variables which are used in the four game models. The notations and meanings of them are listed in Table 1.

Table 1. Model parameters and decision variables.

\begin{tabular}{ll}
\hline Model Parameter & \\
\hline$D$ & the market's total potential demand \\
$D_{1}$ & the demand in the traditional retail channel \\
$D_{2}$ & the demand in the direct channel \\
$c_{m}$ & uint production cost of the green product \\
$\alpha$ & self-price sensitivity coefficient \\
$\beta$ & cross-price sensitivity coefficient \\
$r$ & green sensitivity coefficient \\
$i$ & green investment coefficient \\
\hline Decision Variable & \\
\hline$\theta$ & green degree of the green product \\
$w$ & wholesale price of the green product \\
$p_{r}$ & retail price of the green product \\
$p_{d}$ & direct price of the green product \\
\hline
\end{tabular}

\subsection{Assumptions}

We make the following assumptions, where the parameters and variables are shown in Table 1. 
(1) $p_{r}>w>c_{m}$. In order to ensure profits for the retailer and the manufacturer, the retail price must be higher than the wholesale price, and the wholesale price higher than the production cost.

(2) $\alpha>\beta>0$. This indicates that the customers of a given channel are more sensitive to the price changes in this channel than that in the other channel. This assumption is made in many studies, for instance literature [12].

(3) To advance green product $R \& D$, manufacturers need to invest a lot of funds. In addition, the $R \& D$ cost is assumed as $i \theta^{2}$. This type of cost function is considered in many studies, for instance literature [27].

(4) The demand functions of green product in traditional sale channel and online direct channel are as follows, respectively.

$$
\begin{aligned}
& D_{1}=D-\alpha p_{r}+\beta p_{d}+r \theta \\
& D_{2}=D-\alpha p_{d}+\beta p_{r}+r \theta
\end{aligned}
$$

\subsection{The Profit Functions for Each Player}

Based on the above assumptions, the manufacturer's profit function is:

$$
\pi_{m}=\left(w-c_{m}\right) D_{1}+\left(p_{d}-c_{m}\right) D_{2}-i \theta^{2}
$$

The retailer's profit function is:

$$
\pi_{r}=\left(p_{r}-w\right) D_{1}
$$

The total profit function for the supply chain is:

$$
\pi_{s c}=\left(p_{r}-c_{m}\right) D_{1}+\left(p_{d}-c_{m}\right) D_{2}-i \theta^{2}
$$

\section{The Model}

\subsection{Decentralized Scenario}

In the decentralized scenario, Stackelberg competition between the manufacturer and the retailer is established. As the leader of the competition, the manufacturer determines the green degree of the product, the wholesale price and the direct price; then, the retailer determines the product's retail price correspondingly. The model is formulated as:

$$
\left\{\begin{array}{l}
\max \pi_{m}=\left(w-c_{m}\right) D_{1}+\left(p_{d}-c_{m}\right) D_{2}-i \theta^{2} \\
\text { s.t. } \max \pi_{r}=\left(p_{r}-w\right) D_{1}
\end{array}\right.
$$

Theorem 1. In the decentralized scenario, the optimal green degree, wholesale price, retail price, and direct price are given as follows:

$$
\begin{gathered}
\theta^{M^{*}}=\frac{r(3 \alpha+\beta)\left(D-\alpha c_{m}+\beta c_{m}\right)}{8 \alpha^{2} i-3 \alpha r^{2}-8 \alpha \beta i-\beta r^{2}} \\
w^{M^{*}}=\frac{3 \alpha r^{2} c_{m}-4 \alpha^{2} i c_{m}-4 \alpha i D+\beta r^{2} c_{m}+4 \alpha \beta i c_{m}}{3 \alpha r^{2}+8 \alpha \beta i+\beta r^{2}-8 \alpha^{2} i} \\
p_{r}^{M^{*}}=\frac{3 \alpha r^{2} c_{m}-2 \alpha^{2} i c_{m}-6 \alpha i D+2 \beta^{2} i c_{m}+\beta r^{2} c_{m}+2 \beta i D}{3 \alpha r^{2}+8 \alpha \beta i+\beta r^{2}-8 \alpha^{2} i} \\
p_{d}^{M^{*}}=\frac{3 \alpha r^{2} c_{m}-4 \alpha^{2} i c_{m}-4 \alpha i D+\beta r^{2} c_{m}+4 \alpha \beta i c_{m}}{3 \alpha r^{2}+8 \alpha \beta i+\beta r^{2}-8 \alpha^{2} i}
\end{gathered}
$$

and the profits of the manufacturer, the retailer and the overall GSC are respectively: 


$$
\begin{aligned}
\pi_{m}^{M^{*}} & =\frac{-i(3 \alpha+\beta)\left(D-\alpha c_{m}+\beta c_{m}\right)^{2}}{3 \alpha r^{2}+8 \alpha \beta i+\beta r^{2}-8 \alpha^{2} i} \\
\pi_{r}^{M^{*}} & =\frac{4 \alpha i^{2}(\alpha-\beta)^{2}\left(D-\alpha c_{m}+\beta c_{m}\right)^{2}}{\left(3 \alpha r^{2}+8 \alpha \beta i+\beta r^{2}-8 \alpha^{2} i\right)^{2}} \\
\pi_{s c}^{M^{*}} & =\frac{i\left(D-\alpha c_{m}+\beta c_{m}\right)^{2} A}{\left(3 \alpha r^{2}+8 \alpha \beta i+\beta r^{2}-8 \alpha^{2} i\right)^{2}}
\end{aligned}
$$

The value of $A$ is shown in Appendix A, and the proof of Theorem 1 appears in Appendix B.

\subsection{Centralized Scenario}

In the centralized scenario, the GSC is regarded as a whole. Instead of making decisions based on their own interests, the manufacturer and the retailer make collective decisions to maximize the overall profits of the GSC. As a result, a high requirement is set for the decision-makers. The model is formulated as:

$$
\max \pi_{s c}=\left(p_{r}-c_{m}\right) D_{1}+\left(p_{d}-c_{m}\right) D_{2}-i \theta^{2}
$$

Theorem 2. In the centralized scenario, the optimal green degree, retail price, direct price and the overall profit of the GSC are given as follows:

$$
\begin{gathered}
\theta^{*}=\frac{r\left(D-\alpha c_{m}+\beta c_{m}\right)}{2 \alpha i-r^{2}-2 \beta i} \\
p_{r}^{*}=\frac{D i+\alpha c_{m} i-r^{2} c_{m}-\beta c_{m} i}{2 \alpha i-r^{2}-2 \beta i} \\
p_{d}^{*}=\frac{D i+\alpha c_{m} i-r^{2} c_{m}-\beta c_{m} i}{2 \alpha i-r^{2}-2 \beta i} \\
\pi_{s c}^{*}=\frac{i\left(D-\alpha c_{m}+\beta c_{m}\right)^{2}}{2 \alpha i-r^{2}-2 \beta i}
\end{gathered}
$$

The proof of Theorem 2 appears in Appendix B.

\subsection{Revenue-Sharing Scenario}

In this section, we establish a retailer-led revenue-sharing contract game model and a bargaining revenue-sharing contract game model. In order to advance the green level of the SC, the profit coordination systems are set up in both models to reduce the manufacturer's burden of the green product $R \& D$. That is, the retailer will return a share of retail profits to the manufacturer. The percentage of retailer gain from retail profits is $\lambda(0<\lambda<1)$, and the percentage of manufacturer gain from retail profits is $1-\lambda$.

\subsubsection{Retailer-Led Revenue-Sharing Scenario}

In this model, the retailer determines the revenue-sharing ratio $\lambda$. The manufacturer determines the wholesale price, the price and the green degree, and then the retailer determines the retail price according to the manufacturer's decision. The model is formulated as:

$$
\left\{\begin{array}{l}
\max \pi_{r}=\lambda\left(p_{r}-w\right) D_{1} \\
\text { s.t. } \max \pi_{m}=\left(w-c_{m}\right) D_{1}+\left(p_{d}-c_{m}\right) D_{2}-i \theta^{2}+(1-\lambda)\left(p_{r}-w\right) D_{1}
\end{array}\right.
$$

Theorem 3. In the retailer-led revenue-sharing scenario, the optimal revenue-sharing ratio, green degree, wholesale price, retail price and direct price are: 


$$
\begin{gathered}
\lambda^{R^{*}}=\frac{4 \alpha \beta i+2 \alpha r^{2}-4 \alpha^{2} i}{4 \alpha \beta i+\alpha r^{2}+\beta r^{2}-4 \alpha^{2} i} \\
\theta^{R^{*}}=\frac{r\left(D-\alpha c_{m}+\beta c_{m}\right)\left(3 \alpha^{2} i-2 \alpha \beta i-\alpha r^{2}-\beta^{2} i-\beta r^{2}\right)}{B} \\
w^{R^{*}}=\frac{C c_{m}+\left(8 \alpha^{3} i^{2}-8 \alpha^{2} \beta i^{2}-4 \alpha^{2} r^{2} i+\alpha \beta r^{2} i-\beta^{2} r^{2} i\right) D}{2 \alpha B} \\
p_{r}^{R^{*}}=\frac{E c_{m}+\left(12 \alpha^{2} i^{2}-16 \alpha \beta i^{2}-5 \alpha r^{2} i+4 \beta^{2} i^{2}+\beta r^{2} i\right) D}{2 B} \\
p_{d}^{R^{*}}=\frac{F c_{m}+\left(8 \alpha^{2} i^{2}-8 \alpha \beta i^{2}-3 \alpha r^{2} i-\beta r^{2} i\right) D}{2 B}
\end{gathered}
$$

and the profits of the manufacturer, the retailer and the total supply chain are respectively:

$$
\begin{gathered}
\pi_{m}^{R^{*}}=\frac{\left(D-\alpha c_{m}+\beta c_{m}\right)\left(3 \alpha^{2} i-2 \alpha \beta i-\alpha r^{2}-\beta^{2} i-\beta r^{2}\right)}{B} \\
\pi_{r}^{R^{*}}=\frac{i^{2}(\alpha-\beta)^{2}\left(D-\alpha c_{m}+\beta c_{m}\right)^{2}}{2\left(r^{2}-2 \alpha i+2 \beta i\right)\left(\alpha r^{2}+\beta r^{2}+4 \alpha \beta i-4 \alpha^{2} i\right)} \\
\pi_{s c}^{R^{*}}=\frac{i\left(D-\alpha c_{m}+\beta c_{m}\right)^{2}\left(7 \alpha^{2} i-6 \alpha \beta i-2 \alpha r^{2}-\beta^{2} i-2 \beta r^{2}\right)}{2 B}
\end{gathered}
$$

The values of $B, C, E$ and $F$ are shown in Appendix $A$, and the proof of Theorem 3 appears in Appendix B.

\subsubsection{Bargaining Revenue-Sharing Scenario}

In this model, the revenue-sharing ratio $\lambda$ is determined by the manufacturer and the retailer through bargaining rather than determined by the retailer. The model is formulated as:

$$
\max \pi_{B}=\pi_{m} \pi_{r}
$$

Theorem 4. In the bargaining revenue-sharing scenario, the optimal revenue-sharing ratio, green degree, wholesale price, retail price and direct price are:

$$
\begin{gathered}
\lambda^{B^{*}}=\frac{2 \alpha \beta i+\alpha r^{2}-2 \alpha^{2} i}{4 \alpha \beta i+\alpha r^{2}+\beta r^{2}-4 \alpha^{2} i} \\
\theta^{B^{*}}=\frac{r\left(D-\alpha c_{m}+\beta c_{m}\right)\left(10 \alpha^{2} i-8 \alpha \beta i-3 \alpha r^{2}-2 \beta^{2} i-3 \beta r^{2}\right)}{3 B} \\
w^{B *}=\frac{A_{1} c_{m}+\left(4 \alpha^{2} \beta i^{2}-8 \alpha^{3} i^{2}+4 \alpha^{2} r^{2} i+4 \alpha \beta^{2} i^{2}+2 \beta^{2} r^{2} i\right) D}{3 \alpha B} \\
p_{r}^{B^{*}}=\frac{B_{1} c_{m}+\left(16 \alpha^{2} i^{2}-20 \alpha \beta i^{2}-6 \alpha r^{2} i+4 \beta^{2} i^{2}\right) D}{2 B} \\
p_{d}^{B^{*}}=\frac{C_{1} c_{m}+\left(12 \alpha^{2} i^{2}-12 \alpha \beta i^{2}-4 \alpha r^{2} i-2 \beta r^{2} i^{2}\right) D}{2 B}
\end{gathered}
$$

and the profits of and the profits of the manufacturer, the retailer and the total supply chain are respectively:

$$
\begin{gathered}
\pi_{m}^{B^{*}}=\frac{i\left(D-\alpha c_{m}+\beta c_{m}\right)^{2}\left(10 \alpha^{2} i-8 \alpha \beta i-3 \alpha r^{2}-2 \beta^{2} i-3 \beta r^{2}\right)}{3 B} \\
\pi_{r}^{B^{*}}=\frac{4 i^{2}(\alpha-\beta)^{2}\left(D-\alpha c_{m}+\beta c_{m}\right)^{2}}{9\left(r^{2}-2 \alpha i+2 \beta i\right)\left(\alpha r^{2}+\beta r^{2}+4 \alpha \beta i-4 \alpha^{2} i\right)}
\end{gathered}
$$




$$
\pi_{s c}^{B^{*}}=\frac{i\left(D-\alpha c_{m}+\beta c_{m}\right)^{2}\left(34 \alpha^{2} i-32 \alpha \beta i-9 \alpha r^{2}-2 \beta^{2} i-9 \beta r^{2}\right)}{9 B}
$$

The values of $A_{1}, B_{1}$ and $C_{1}$ are shown in Appendix $\mathrm{A}$, and the proof of Theorem 4 appears in Appendix B.

\section{Model Comparison}

Equilibrium solutions of the four models are shown in Table 2.

By comparing and analyzing the equilibrium solutions of the four game models, we draw the following conclusions:

Corollary 1. The optimal green degrees of the four models in descending order are: $\theta^{*}>\theta^{B^{*}}>\theta^{R^{*}}>\theta^{M^{*}}$.

By comparing green degrees of the four models, corollary 1 shows that the optimal green degree is highest in the centralized scenario and lowest in the decentralized scenario. Although the centralized decision model has the best green performance, it is difficult to achieve in reality due to the high requirement for decision-makers. Thus, the two revenue-sharing game models, in which the green degrees are neither the highest nor the lowest, seem to have more practical significance.

Corollary 2. The sensitivities of the optimal green degrees to parameter $r$ and $i$ are as follows:

(1) $\frac{\partial \theta^{M^{*}}}{\partial r}>0, \frac{\partial \theta^{*}}{\partial r}>0, \frac{\partial \theta^{R^{*}}}{\partial r}>0$ and $\frac{\partial \theta^{B^{*}}}{\partial r}>0$;

(2) $\frac{\partial \theta^{M^{*}}}{\partial i}<0, \frac{\partial \theta^{*}}{\partial i}<0, \frac{\partial \theta^{R^{*}}}{\partial i}<0$ and $\frac{\partial \theta^{B^{*}}}{\partial i}<0$.

Corollary 2 shows that the green degree of green product is proportional to customers' green sensitivity, but inversely proportional to green investment coefficient. This indicates that the increase of customers' environmental awareness is a driver for advancing the green level of the product, while $R \& D$ cost is a barrier.

Corollary 3. The optimal retail prices, wholesale prices and direct prices of the four models in descending order are:

(1) $p_{r}^{M^{*}}>p_{r}^{R^{*}}>p_{r}^{B^{*}}>p_{r}^{*}$;

(2) $w^{M^{*}}>w^{R^{*}}>w^{B^{*}}$;

(3) $p_{d}^{*}>p_{d}^{B^{*}}>p_{d}^{R^{*}}>p_{d}^{M^{*}}$.

The optimal retail price of green products is highest in the decentralized scenario, and lowest in the centralized scenario. The optimal wholesale price is highest in the decentralized scenario, and lowest in the Bargaining revenue-sharing scenario. The optimal direct price is highest in the centralized scenario, and lowest in the decentralized scenario. Given that the centralized model aims at the overall profit of the GSC and does not focus on the profit distribution in GSC, the wholesale price is neglected in Corollary 3.

Corollary 4. The optimal manufacturer's profit, retailer's profit and the overall profit of the SC in descending order are:

(1) $\pi_{m}^{B^{*}}>\pi_{m}^{R^{*}}>\pi_{m}^{M^{*}}$;

(2) $\pi_{r}^{R^{*}}>\pi_{r}^{M^{*}}>\pi_{r}^{B^{*}}$;

(3) $\pi_{s c}^{*}>\pi_{s c}^{B^{*}}>\pi_{s c}^{R^{*}}>\pi_{s c}^{M^{*}}$. 
Table 2. Equilibrium solutions.

\begin{tabular}{|c|c|c|c|c|}
\hline & Decentralized Scenario & Centralized Scenario & Retailer-Led Revenue-Sharing & Bargaining Revenue-Sharing \\
\hline$\lambda$ & - & - & $\frac{4 \alpha \beta i+2 \alpha r^{2}-4 \alpha^{2} i}{4 \alpha \beta i+\alpha r^{2}+\beta r^{2}-4 \alpha^{2} i}$ & $\frac{2 \alpha \beta i+\alpha r^{2}-2 \alpha^{2} i}{4 \alpha \beta i+\alpha r^{2}+\beta r^{2}-4 \alpha^{2} i}$ \\
\hline$\theta$ & $\frac{r(3 \alpha+\beta)\left(D-\alpha c_{m}+\beta c_{m}\right)}{8 \alpha^{2} i-3 \alpha r^{2}-8 \alpha \beta i-\beta r^{2}}$ & $\frac{r\left(D-\alpha c_{m}+\beta c_{m}\right)}{2 \alpha i-r^{2}-2 \beta i}$ & $\frac{r\left(D-\alpha c_{m}+\beta c_{m}\right)\left(3 \alpha^{2} i-2 \alpha \beta i-\alpha r^{2}-\beta^{2} i-\beta r^{2}\right)}{B}$ & $\frac{r\left(D-\alpha c_{m}+\beta c_{m}\right)\left(10 \alpha^{2} i-8 \alpha \beta i-3 \alpha r^{2}-2 \beta^{2} i-3 \beta r^{2}\right)}{3 B}$ \\
\hline$w$ & $\frac{3 \alpha r^{2} c_{m}-4 \alpha^{2} i c_{m}-4 \alpha i D+\beta r^{2} c_{m}+4 \alpha \beta i c_{m}}{3 \alpha r^{2}+8 \alpha \beta i+\beta r^{2}-8 \alpha^{2} i}$ & - & $\frac{C c_{m}+\left(8 \alpha^{3} i^{2}-8 \alpha^{2} \beta i^{2}-4 \alpha^{2} r^{2} i+\alpha \beta r^{2} i-\beta^{2} r^{2} i\right) D}{2 \alpha B}$ & $\frac{A_{1} c_{m}+\left(4 \alpha^{2} \beta i^{2}-8 \alpha^{3} i^{2}+4 \alpha^{2} r^{2} i+4 \alpha \beta^{2} i^{2}+2 \beta^{2} r^{2} i\right) D}{3 \alpha B}$ \\
\hline$p_{r}$ & $\frac{3 \alpha r^{2} c_{m}-2 \alpha^{2} i c_{m}-6 \alpha i D+2 \beta^{2} i c_{m}+\beta r^{2} c_{m}+2 \beta i D}{3 \alpha r^{2}+8 \alpha \beta i+\beta r^{2}-8 \alpha^{2} i}$ & $\frac{D i+\alpha c_{m} i-r^{2} c_{m}-\beta c_{m} i}{2 \alpha i-r^{2}-2 \beta i}$ & $\frac{E c_{m}+\left(12 \alpha^{2} i^{2}-16 \alpha \beta i^{2}-5 \alpha r^{2} i+4 \beta^{2} i^{2}+\beta r^{2} i\right) D}{2 B}$ & $\frac{B_{1} c_{m}+\left(16 \alpha^{2} i^{2}-20 \alpha \beta i^{2}-6 \alpha r^{2} i+4 \beta^{2} i^{2}\right) D}{2 B}$ \\
\hline$p_{d}$ & $\frac{3 \alpha r^{2} c_{m}-4 \alpha^{2} i c_{m}-4 \alpha i D+\beta r^{2} c_{m}+4 \alpha \beta i c_{m}}{3 \alpha r^{2}+8 \alpha \beta i+\beta r^{2}-8 \alpha^{2} i}$ & $\frac{D i+\alpha c_{m} i-r^{2} c_{m}-\beta c_{m} i}{2 \alpha i-r^{2}-2 \beta i}$ & $\frac{F c_{m}+\left(8 \alpha^{2} i^{2}-8 \alpha \beta i^{2}-3 \alpha r^{2} i-\beta r^{2} i\right) D}{2 B}$ & $\frac{C_{1} c_{m}+\left(12 \alpha^{2} i^{2}-12 \alpha \beta i^{2}-4 \alpha r^{2} i-2 \beta r^{2} i^{2}\right) D}{2 B}$ \\
\hline$\pi_{m}$ & $\frac{-i(3 \alpha+\beta)\left(D-\alpha c_{m}+\beta c_{m}\right)^{2}}{3 \alpha r^{2}+8 \alpha \beta i+\beta r^{2}-8 \alpha^{2} i}$ & - & $\frac{\left(D-\alpha c_{m}+\beta c_{m}\right)\left(3 \alpha^{2} i-2 \alpha \beta i-\alpha r^{2}-\beta^{2} i-\beta r^{2}\right)}{B}$ & $\frac{i\left(D-\alpha c_{m}+\beta c_{m}\right)^{2}\left(10 \alpha^{2} i-8 \alpha \beta i-3 \alpha r^{2}-2 \beta^{2} i-3 \beta r^{2}\right)}{3 B}$ \\
\hline$\pi_{r}$ & $\frac{4 \alpha i^{2}(\alpha-\beta)^{2}\left(D-\alpha c_{m}+\beta c_{m}\right)^{2}}{\left(3 \alpha r^{2}+8 \alpha \beta i+\beta r^{2}-8 \alpha^{2} i\right)^{2}}$ & - & $\frac{i^{2}(\alpha-\beta)^{2}\left(D-\alpha c_{m}+\beta c_{m}\right)^{2}}{2\left(r^{2}-2 \alpha i+2 \beta i\right)\left(\alpha r^{2}+\beta r^{2}+4 \alpha \beta i-4 \alpha^{2} i\right)}$ & $\frac{4 i^{2}(\alpha-\beta)^{2}\left(D-\alpha c_{m}+\beta c_{m}\right)^{2}}{9\left(r^{2}-2 \alpha i+2 \beta i\right)\left(\alpha r^{2}+\beta r^{2}+4 \alpha \beta i-4 \alpha^{2} i\right)}$ \\
\hline$\pi_{s c}$ & $\frac{i\left(D-\alpha c_{m}+\beta c_{m}\right)^{2} A}{\left(3 \alpha r^{2}+8 \alpha \beta i+\beta r^{2}-8 \alpha^{2} i\right)^{2}}$ & $\frac{i\left(D-\alpha c_{m}+\beta c_{m}\right)^{2}}{2 \alpha i-r^{2}-2 \beta i}$ & $\frac{i\left(D-\alpha c_{m}+\beta c_{m}\right)^{2}\left(7 \alpha^{2} i-6 \alpha \beta i-2 \alpha r^{2}-\beta^{2} i-2 \beta r^{2}\right)}{2 B}$ & $\frac{i\left(D-\alpha c_{m}+\beta c_{m}\right)^{2}\left(34 \alpha^{2} i-32 \alpha \beta i-9 \alpha r^{2}-2 \beta^{2} i-9 \beta r^{2}\right)}{9 B}$ \\
\hline
\end{tabular}

The values of $A, B, C, E, F, A_{1}, B_{1}$ and $C_{1}$ are shown in Appendix A. 
The optimal manufacturer's profit is highest in the Bargaining revenue-sharing scenario, and lowest in the decentralized scenario. The optimal retailer's profit is highest in the Retailer-led revenue-sharing scenario, and lowest in the Bargaining revenue-sharing scenario. The optimal overall profit of the GSC is highest in the centralized scenario, and lowest in the decentralized scenario. Corollary 4 indicates that Revenue-sharing game models can attain better economic goals and coordinate participants interest of the GSC.

Corollary 5. The comparisons of optimal prices and of demands between the traditional channel and the direct online channel are given as follows:

(1) $p_{d}^{*}=p_{r}^{*}, \quad p_{d}^{M^{*}}<p_{r}^{M^{*}}, \quad p_{d}^{B^{*}}<p_{r}^{B^{*}}, \quad p_{d}^{R^{*}}<p_{r}^{R^{*}}$;

(2) $D_{1}^{*}=D_{2}^{*}, \quad D_{1}^{M^{*}}<D_{2}^{M^{*}}, \quad D_{1}^{B^{*}}<D_{2}^{B^{*}}, \quad D_{1}^{R^{*}}<D_{2}^{R^{*}}$

In the centralized scenario, the optimal direct price is equal to the optimal retail price. In the other three scenarios, the optimal direct price is less than the optimal retail price. Similarly, in the centralized scenario, the demands in the two channels are equal. In the other three scenarios, the demand in the direct channel is larger than the demand in the traditional channel. With the rapid development of the Internet, the online sale has become a major distribution channel of the GSC.

\section{Numerical Analysis}

In this section, a numerical example is provided to illustrate the feasibility of the proposed problem solution. Based on the problem assumptions, parameter values are set as: $D=1000, \alpha=60, \beta=30$ and $c_{m}=5$.

As shown in Figure 2, the green degree $(\theta)$ increases with the increase of the customer green sensitivity coefficient $(r)$, and decreases with the increase of the green investment coefficient $(i)$. Correspondingly, when the customer green sensitivity coefficient is at the maximum and green investment coefficient is at the minimum, the green degree reaches the maximum. These indicate that customers' green sensitivity and preference could promote the improvement of the products' green level, and the high R\&D risks may impede such improvement.

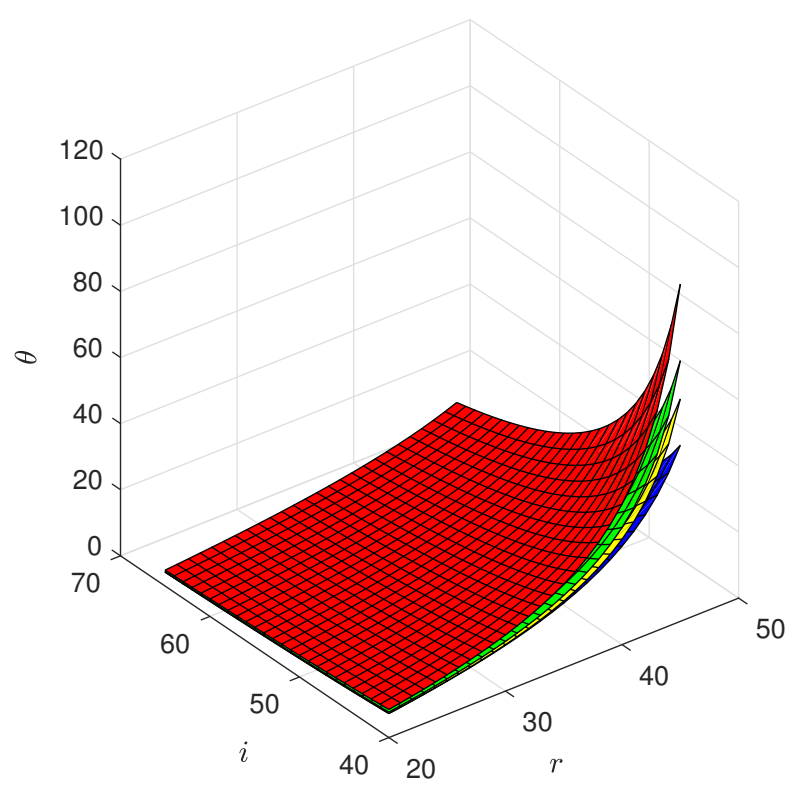

The centralized scenario

The decentralized scenario Retailer-led revenue-sharing Bargaining revenue-sharing

Figure 2. The optimal green degree $\theta$ vs $r$ and $i$. 
In Figure 3, The manufacturer's profit $\left(\pi_{m}\right)$ increases with the increase of the customer green sensitivity coefficient $(r)$, and declines with the increase of the green investment coefficient $(i)$. Correspondingly, when the customer green sensitivity coefficient is at the maximum and green investment coefficient is at the minimum, the manufacturer's profit reaches the maximum. These indicate that customers' sensitivity and preference to green products could increase the profit of the green manufacturer, and the high $R \& D$ cost may reduce the profit.

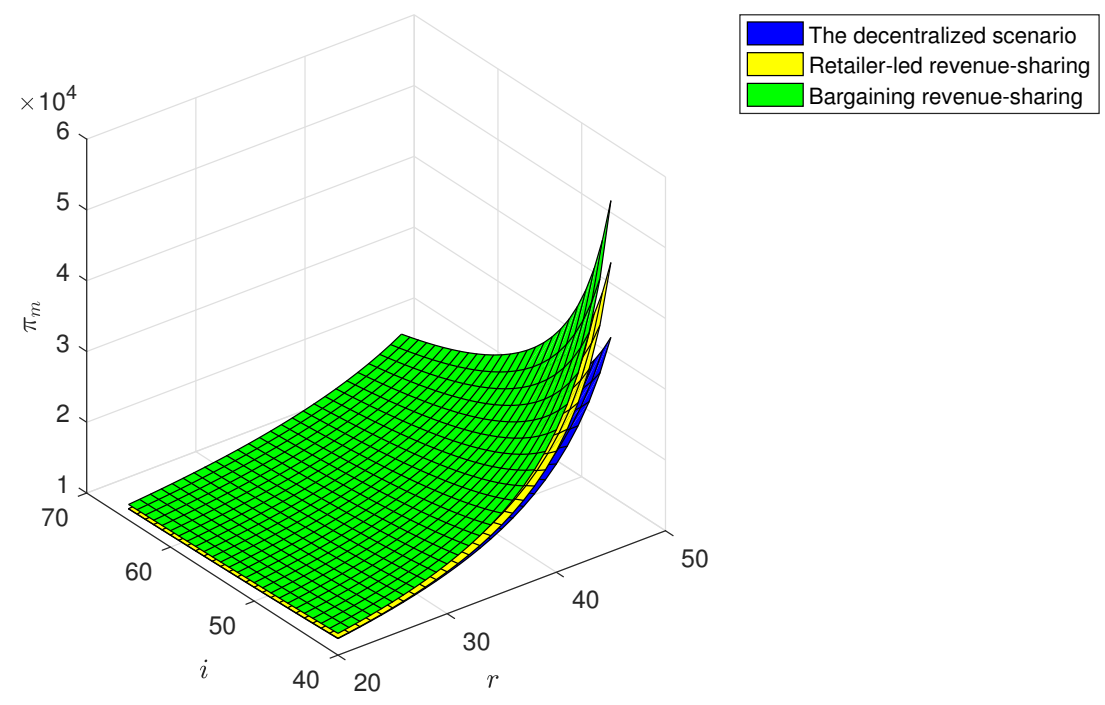

Figure 3. The optimal manufacturer's profit $\pi_{m}$ vs $r$ and $i$.

As shown in Figure 4, the retailer's profit $\left(\pi_{r}\right)$ increases with the increase of the customer green sensitivity coefficient $(r)$, and decreases with the increase of the green investment coefficient $(i)$. Correspondingly, when the customer green sensitivity coefficient is at the maximum and green investment coefficient is at the minimum, the retailer's profit reaches the maximum. Customer purchasing habits could deeply impact the profit of the retailer. On one hand, customer green consciousness could lead to profit growth. On the other hand, green products R\&D may incur higher costs and price, which may drive away price-sensitive customers.

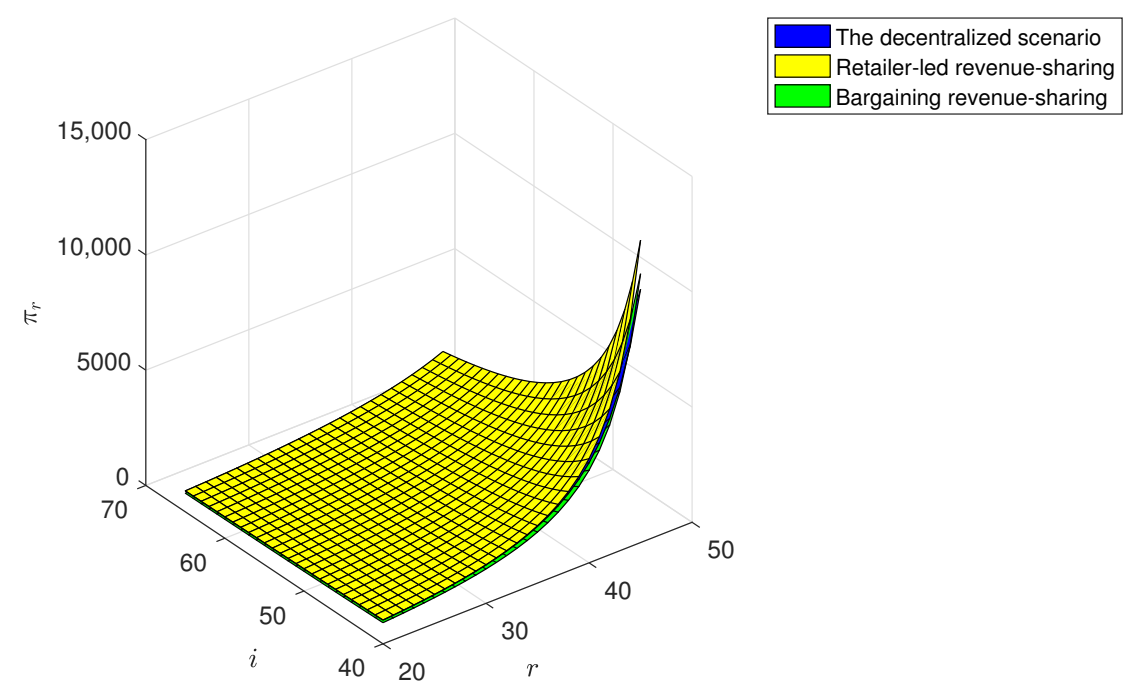

Figure 4. The optimal retailer's profit $\pi_{r}$ vs $r$ and $i$. 
In Figure 5, The overall profit of the GSC $\left(\pi_{s c}\right)$ increases with the increase of the customer green sensitivity coefficient $(r)$, and declines with the increase of the green investment coefficient $(i)$. Correspondingly, when the customer green sensitivity coefficient is at the maximum and green investment coefficient is at the minimum, the overall profit of the GSC reaches the maximum. Customer green consciousness could promote the economic performance of the GSC. However, high green products R\&D risks may be an impediment.

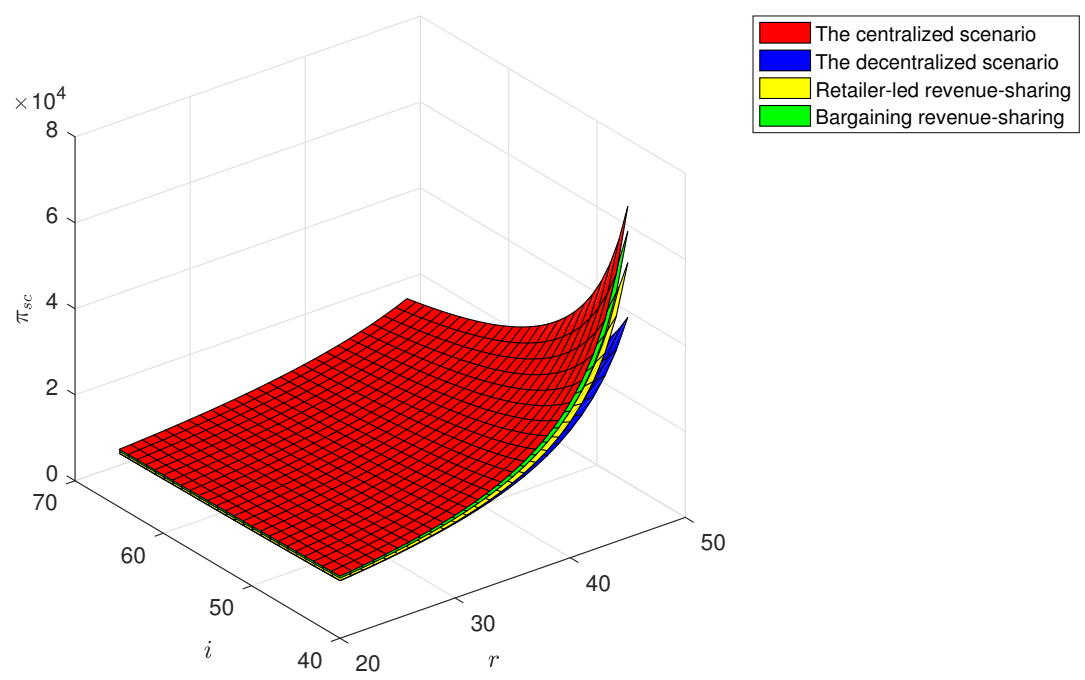

Figure 5. The optimal overall profit $\pi_{s c}$ vs $r$ and $i$.

\section{Conclusions}

In this paper, we investigate the alignment issues between green level and economic performance of GSC. We are particularly interested to see how the alignment may be achieved through competition and cooperation of the GSC participants. To answer this question, we take into account a dual-distribution GSC composed of a manufacturer, a retailer and customers. Based on this, four game models are established, namely decentralized scenario, centralized scenario, retailer-led revenue-sharing scenario and bargaining revenue-sharing scenario. Moreover, coefficients which represent green product $R \& D$ cost, customer green sensitivity and price sensitivity, are introduced into the above models. We compared the optimal decisions of the four game models. We also discussed the impact of green sensitivity and green R\&D cost. Main findings are summarized as follows:

(1) In terms of green degree and profitability, centralized scenario and the two revenue-sharing scenarios are better than decentralized scenario, which indicates that cooperation between the manufacturer and the retailer is more conducive to the GSC's economic and environmental performance than competition. Given that centralized scenario is difficult to realize due to the high requirement for cooperation level and decision-makers, the two revenue-sharing scenarios are recommended for GSCM practice to achieve the integration of economic and environmental goals.

(2) Driven by the increase of customer green sensitivity, green degree of product will improve, and profits of the manufacturer, the retailer and the overall GSC will rise. In contrast to customer green sensitivity, high green $R \& D$ cost is an obstacle for green innovation and profit growth. Therefore, improving green awareness and reducing green $R \& D$ cost will raise green level and profitability of the GSC. Since new technologies always come with additional costs, it is difficult to reduce green R\&D cost in reality. Consequently, advocating environmental awareness and promoting green consumption are of vital importance to the GSCM practice.

(3) In the centralized scenario, the demands in the two channels are equal. In the other three scenarios, the demand in the direct online channel is larger than the demand in the traditional channel. 
These indicate that the Internet has significantly changed consumption patterns and sale modes, and the online sale has become a major distribution channel of the GSC.

This study has several shortcomings. First, our models assume all of the parameters are certain and deterministic. However, uncertainty widely exists in GSC in reality. Thus, introducing uncertainty into our models for future study is worthwhile. Second, our models use linear demand functions, which have some limitations on simulating the complex activities of GSC. Therefore, establishing non-linear demand functions is the future research direction. Finally, this paper takes customer environmental awareness as a driver promoting the implementation of GSCM. Drivers such as investor focuses, environmental policies and government subsidy may also be important and should be considered in our future study.

Author Contributions: W.M. and Z.C. conceived and designed the study; W.M. and Z.C. contributed analysis tools; W.M. and Z.C. wrote the paper; S.X. offered some advice.

Funding: This research received no external funding

Conflicts of Interest: The authors declare no conflicts of interest.

\section{Appendix A}

$$
\begin{aligned}
& A=28 \alpha^{3} i-24 \alpha^{2} \beta i-9 \alpha^{2} r^{2}-4 \alpha \beta^{2} i-6 \alpha \beta r^{2}-\beta^{2} r^{2} \\
& B=8 \alpha^{3} i^{2}-16 \alpha^{2} \beta i^{2}-6 \alpha^{2} r^{2} i+8 \alpha \beta^{2} i^{2}+4 \alpha \beta r^{2} i+\alpha r^{4}+2 \beta^{2} r^{2} i+\beta r^{4} \\
& C=8 \alpha^{4} i^{2}-16 \alpha^{3} \beta i^{2}-8 \alpha^{3} r^{2} i+8 \alpha^{2} \beta^{2} i^{2}+3 \alpha^{2} \beta r^{2} i+3 \alpha^{2} r^{4}+6 \alpha \beta^{2} r^{2} i+2 \alpha \beta r^{4}-\beta^{3} r^{2} i \\
& E=4 \alpha^{3} i^{2}-4 \alpha^{2} \beta i^{2}-7 \alpha^{2} r^{2} i-4 \alpha \beta^{2} i^{2}+2 \alpha \beta r^{2} i+2 \alpha r^{4}+4 \beta^{3} i^{2}+5 \beta^{2} r^{2} i+2 \beta r^{4} \\
& F=8 \alpha^{3} i^{2}-16 \alpha^{2} \beta i^{2}-9 \alpha^{2} r^{2} i+8 \alpha \beta^{2} i^{2}+6 \alpha \beta r^{2} i+2 \alpha r^{4}+3 \beta^{2} r^{2} i+2 \beta r^{4} \\
& A_{1}=-16 \alpha^{4} i^{2}+36 \alpha^{3} \beta i^{2}+14 \alpha^{3} r^{2} i-24 \alpha^{2} \beta^{2} i^{2}-8 \alpha^{2} \beta r^{2} i-3 \alpha^{2} r^{4}+4 \alpha \beta^{3} i^{2}-8 \alpha \beta^{2} r^{2} i-3 \alpha \beta r^{4}+2 \beta^{3} r^{2} i \\
& B_{1}=8 \alpha^{3} i^{2}-12 \alpha^{2} \beta i^{2}-12 \alpha^{2} i r^{2}+6 \alpha \beta i r^{2}+3 \alpha r^{4}+4 \beta^{3} r^{2}+6 \beta^{2} i r^{2}+3 \beta r^{4} \\
& C_{1}=12 \alpha^{3} i^{2}-24 \alpha^{2} \beta i^{2}-14 \alpha^{2} i r^{2}+12 \alpha \beta^{2} i^{2}+10 \alpha \beta r^{2}+3 \alpha r^{4}+4 \beta^{2} r^{2} i+3 \beta r^{4}
\end{aligned}
$$

\section{Appendix B}

Proof of of Theorem 1. Using the backward induction method, Equation (4) can be written as:

$$
\pi_{r}=\left(p_{r}-w\right)\left(D-\alpha p_{r}+\beta p_{d}+r \theta\right)
$$

The second derivatives of $p_{r}$ is $\frac{\mathrm{d}^{2} \pi_{r}}{\mathrm{~d} p_{r}^{2}}=-2 \alpha<0$, so $p i_{r}$ is a strictly concave function of $p_{r}$.

We set the first derivatives of $p_{r}$ equal to zero, we get:

$$
p_{r}=\frac{D+\beta p_{d}+r \theta+\alpha w}{2 \alpha}
$$

We put Equation (A2) to Equation (3), and get the Hesssian matrix:

$$
H\left(\pi_{m}\right)=\left[\begin{array}{ccc}
\frac{\partial^{2} \pi_{m}}{\partial p_{d}^{2}} & \frac{\partial^{2} \pi_{m}}{\partial p_{d} \partial w} & \frac{\partial^{2} \pi_{m}}{\partial p_{d} \partial \theta} \\
\frac{\partial^{2} \pi_{m}}{\partial w \partial p_{d}} & \frac{\partial^{2} \pi_{m}}{\partial w^{2}} & \frac{\partial^{2} \pi_{m}}{\partial w \partial \theta} \\
\frac{\partial^{2} \pi_{m}}{\partial \theta \partial p_{d}} & \frac{\partial^{2} \pi_{m}}{\partial \theta \partial w} & \frac{\partial^{2} \pi_{m}}{\partial \theta^{2}}
\end{array}\right]=\left[\begin{array}{ccc}
\frac{\beta^{2}-2 \alpha^{2}}{\alpha} & \beta & \frac{(2 \alpha+\beta) r}{2 \alpha} \\
\beta & -\alpha & \frac{r}{2} \\
\frac{(2 \alpha+\beta) r}{2 \alpha} & \frac{r}{2} & -2 i
\end{array}\right]
$$


The leading principal minors are

$$
\begin{gathered}
M_{1}=\frac{\beta^{2}-2 \alpha^{2}}{\alpha} \\
M_{2}=\frac{2 \alpha^{3}-2 \alpha \beta^{2}}{\alpha} \\
M_{3}=\frac{-8 \alpha^{3} i+3 \alpha^{2} r^{2}+8 \alpha \beta^{2} i+4 \alpha \beta r^{2}+\beta^{2} r^{2}}{2 \alpha}
\end{gathered}
$$

When $M_{1}<0, M_{2}>0$ and $M_{3}<0$, which is $-8 \alpha^{3} i+3 \alpha^{2} r^{2}+8 \alpha \beta^{2} i+4 \alpha \beta r^{2}+\beta^{2} r^{2}<0$, the Hessian matrix is negative definite.

By solving $\frac{\partial \pi_{m}}{\partial p_{d}}=0, \frac{\partial \pi_{m}}{\partial w}=0$ and $\frac{\partial \pi_{m}}{\partial \theta}=0$, we get the optimal direct price, the optimal wholesale price and the optimal product green degree:

$$
\begin{gathered}
p_{d}^{M^{*}}=\frac{3 \alpha r^{2} c_{m}-4 \alpha^{2} i c_{m}-4 \alpha i D+\beta r^{2} c_{m}+4 \alpha \beta i c_{m}}{3 \alpha r^{2}+8 \alpha \beta i+\beta r^{2}-8 \alpha^{2} i} \\
w^{M^{*}}=\frac{3 \alpha r^{2} c_{m}-4 \alpha^{2} i c_{m}-4 \alpha i D+\beta r^{2} c_{m}+4 \alpha \beta i c_{m}}{3 \alpha r^{2}+8 \alpha \beta i+\beta r^{2}-8 \alpha^{2} i} \\
\theta^{M^{*}}=\frac{r(3 \alpha+\beta)\left(D-\alpha c_{m}+\beta c_{m}\right)}{8 \alpha^{2} i-3 \alpha r^{2}-8 \alpha \beta i-\beta r^{2}}
\end{gathered}
$$

We put Equations (A7)-(A9) into Equation (A2), and get:

$$
p_{r}^{M^{*}}=\frac{3 \alpha r^{2} c_{m}-2 \alpha^{2} i c_{m}-6 \alpha i D+2 \beta^{2} i c_{m}+\beta r^{2} c_{m}+2 \beta i D}{3 \alpha r^{2}+8 \alpha \beta i+\beta r^{2}-8 \alpha^{2} i}
$$

We put Equations (A7)-(A10) into Equations (3), (4) and (5), we get $\pi_{m}^{M^{*}}, \pi_{r}^{M^{*}}$ and $\pi_{s c}^{M^{*}}$. The values are shown in Table 2.

Proof of Theorem 2. The Hessian matrix obtained from Equation (5) is as follows:

$$
H\left(\pi_{s c}\right)=\left[\begin{array}{ccc}
\frac{\partial^{2} \pi_{s c}}{\partial p_{d}^{2}} & \frac{\partial^{2} \pi_{s c}}{\partial p_{d} \partial p_{r}} & \frac{\partial^{2} \pi_{s c}}{\partial p_{d} \partial \theta} \\
\frac{\partial^{2} \pi_{s c}}{\partial p_{r} \partial p_{d}} & \frac{\partial^{2} \pi_{s c}}{\partial p_{r}^{2}} & \frac{\partial^{2} \pi_{s c}}{\partial p_{r} \partial \theta} \\
\frac{\partial^{2} \pi_{s c}}{\partial \theta \partial p_{d}} & \frac{\partial^{2} \pi_{s c}}{\partial \theta \partial p_{r}} & \frac{\partial^{2} \pi_{s c}}{\partial \theta^{2}}
\end{array}\right]=\left[\begin{array}{ccc}
-2 \alpha & 2 \beta & r \\
2 \beta & -2 \alpha & r \\
r & r & -2 i
\end{array}\right]
$$

The leading principal minors are:

$$
\begin{gathered}
M_{1}=-2 \alpha \\
M_{2}=4 \alpha^{2}-4 \beta^{2} \\
M_{3}=4 \alpha r^{2}+8 \beta^{2} i+4 \beta r^{2}-8 \alpha^{2} i
\end{gathered}
$$

When $\alpha r^{2}+2 \beta^{2} i+\beta r^{2}-2 \alpha^{2} i<0$, the Hessian matrix is negative. By solving $\frac{\partial \pi_{s c}}{\partial p_{d}}=0, \frac{\partial \pi_{s c}}{\partial p_{r}}=0$ and $\frac{\partial \pi_{s c}}{\partial \theta}=0$, we get the optimal product green degree, the optimal retail price and the optimal direct price:

$$
\theta^{*}=\frac{r\left(D-\alpha c_{m}+\beta c_{m}\right)}{2 \alpha i-r^{2}-2 \beta i}
$$




$$
\begin{aligned}
& p_{r}^{*}=\frac{D i+\alpha c_{m} i-r^{2} c_{m}-\beta c_{m} i}{2 \alpha i-r^{2}-2 \beta i} \\
& p_{d}^{*}=\frac{D i+\alpha c_{m} i-r^{2} c_{m}-\beta c_{m} i}{2 \alpha i-r^{2}-2 \beta i}
\end{aligned}
$$

We put Equations (A15)-(A17) into Equation (5), and get:

$$
\pi_{s c}^{*}=\frac{i\left(D-\alpha c_{m}+\beta c_{m}\right)^{2}}{2 \alpha i-r^{2}-2 \beta i}
$$

Proof of of Theorem 3. The profit functions for the retailer and the manufacturer are as follows:

$$
\begin{gathered}
\pi_{r}=\lambda\left(p_{r}-w\right) D_{1} \\
\pi_{m}=\left(w-c_{m}\right) D_{1}+\left(p_{d}-c_{m}\right) D_{2}-i \theta^{2}+(1-\lambda)\left(p_{r}-w\right) D_{1}
\end{gathered}
$$

According to Equations (A19), we get $\frac{\partial^{2} \pi_{r}}{\partial p_{r}^{2}}=-2 \lambda \alpha<0$. So Equation (A19) is a strictly concave function of $p_{r}$.

By solving $\frac{\partial \pi_{r}}{\partial p_{r} 2}=0$, we can get :

$$
p_{r}=\frac{D+\beta p_{d}+r \theta+\alpha w}{2 \alpha}
$$

We put Equation (A21) into Equations (A20), and get that the Hesssian of Equations (A20) is negative definite. We set the first derivatives of $p_{d}, w$ and $\theta$ equal to zero, we can get:

$$
\begin{gathered}
p_{d}(\lambda)=\frac{\left(2 \alpha r^{2}-2 \alpha^{2} i c_{m}-2 \alpha i D+2 \alpha \beta i c_{m}\right)-\left(2 \alpha i D+2 \alpha^{2} i c_{m}-\alpha r^{2} c_{m}-\beta r^{2} c_{m}-2 \alpha \beta i c_{m}\right) \lambda}{2 \alpha r^{2}-4 \alpha^{2} i+4 \alpha \beta i-\left(4 \alpha^{2} i-4 \alpha \beta i-\alpha r^{2}-\beta r^{2}\right) \lambda} \\
w(\lambda)=\frac{\left(2 \alpha r^{2}-4 \alpha^{2} i c_{m}-2 \beta^{2} i c_{m}-2 \beta i D+6 \alpha \beta i c_{m}\right)-\left(4 \alpha i D-2 \beta i D-2 \beta^{2} i c_{m}-\alpha r^{2} c_{m}-\beta R^{2} c_{m}\right) \lambda}{2 \alpha r^{2}-4 \alpha^{2} i+4 \alpha \beta i-\left(4 \alpha^{2} i-4 \alpha \beta i-\alpha r^{2}-\beta r^{2}\right) \lambda} \\
\theta(\lambda)=\frac{2 \alpha^{2} r c_{m}-2 \alpha r D-2 \alpha \beta r c_{m}-\left(\alpha r D+\beta r D-\alpha^{2} r c_{m}+\beta r c_{m}\right) \lambda}{2 \alpha r^{2}-4 \alpha^{2} i+4 \alpha \beta i-\left(4 \alpha^{2} i-4 \alpha \beta i-\alpha r^{2}-\beta r^{2}\right) \lambda}
\end{gathered}
$$

We put Equations (A22)-(A24) into (A21):

$$
p_{r}(\lambda)=\frac{2 \alpha^{2} r c_{m}-2 \alpha^{2} i c_{m}-2 \alpha i D+2 \alpha \beta i c_{m}-\left(4 \alpha i D-2 \beta i D-2 \beta^{2} i c_{m} \alpha r^{2} c_{m}-\beta r^{2} c_{m}+2 \alpha \beta i c_{m}\right) \lambda}{2 \alpha r^{2}-4 \alpha^{2} i+4 \alpha \beta i-\left(4 \alpha^{2} i-4 \alpha \beta i-\alpha r^{2}-\beta r^{2}\right) \lambda}
$$

We put Equations (A22)-(A25) into (A19), and get the second derivatives of $\lambda$ is less than zero. By setting the first derivatives of $\lambda$ equal to zero, we get the optimal revenue-sharing ratio:

$$
\lambda^{R^{*}}=\frac{4 \alpha \beta i+2 \alpha r^{2}-4 \alpha^{2} i}{4 \alpha \beta i+\alpha r^{2}+\beta r^{2}-4 \alpha^{2} i}
$$

We put (A26) into (A22)-(A25), and can get:

$$
\begin{aligned}
\theta^{R^{*}} & =\frac{r\left(D-\alpha c_{m}+\beta c_{m}\right)\left(3 \alpha^{2} i-2 \alpha \beta i-\alpha r^{2}-\beta^{2} i-\beta r^{2}\right)}{B} \\
w^{R^{*}} & =\frac{C c_{m}+\left(8 \alpha^{3} i^{2}-8 \alpha^{2} \beta i^{2}-4 \alpha^{2} r^{2} i+\alpha \beta r^{2} i-\beta^{2} r^{2} i\right) D}{2 \alpha B}
\end{aligned}
$$




$$
\begin{gathered}
p_{r}^{R^{*}}=\frac{E c_{m}+\left(12 \alpha^{2} i^{2}-16 \alpha \beta i^{2}-5 \alpha r^{2} i+4 \beta^{2} i^{2}+\beta r^{2} i\right) D}{2 B} \\
p_{d}^{R^{*}}=\frac{F c_{m}+\left(8 \alpha^{2} i^{2}-8 \alpha \beta i^{2}-3 \alpha r^{2} i-\beta r^{2} i\right) D}{2 B}
\end{gathered}
$$

Then we can get $\pi_{m}^{R^{*}}, \pi_{r}^{R^{*}}$ and $\pi_{s c}^{R^{*}}$. The values are shown in Table 2 .

Proof of Theorem 4. We put (A22)-(A25) into (A19) and (A20), and can get:

$$
\pi_{B}(\lambda)=\frac{4 \alpha i^{3} \lambda(\alpha-\beta)^{2}\left(D-\alpha c_{m}+\beta c_{m}\right)^{4}}{\left(4 \alpha^{2} i+4 \alpha^{2} i \lambda-2 \alpha r^{2}-\alpha r^{2} \lambda-\beta r^{2} \lambda-4 \alpha \beta i-4 \alpha \beta i \lambda\right)^{3}}
$$

Similarly, we get the first and second derivatives of $\lambda$ for the Equation (A31). By solving $\frac{d \pi_{B}}{d \lambda}=0$, we can get:

$$
\lambda^{B^{*}}=\frac{2 \alpha \beta i+\alpha r^{2}-2 \alpha^{2} i}{4 \alpha \beta i+\alpha r^{2}+\beta r^{2}-4 \alpha^{2} i}
$$

We put (A32) into the previous expressions, and get $\theta^{B^{*}}, w^{B^{*}}, p_{d}^{B^{*}}, p_{r}^{B^{*}}, \pi_{m}^{B^{*}}, \pi_{r}^{B^{*}}$ and $\pi_{s c}^{B^{*}}$. The values are shown in Table 2.

Proof of Corollary 1. $\because \pi_{s c}^{*}=\frac{i\left(D-\alpha c_{m}+\beta c_{m}\right)^{2}}{2 \alpha i-r^{2}-2 \beta i}>0$ and $i>0$

$\therefore 2 \alpha i-r^{2}-2 \beta i>0$

$\because \theta^{*}=\frac{r\left(D-\alpha c_{m}+\beta c_{m}\right)}{2 \alpha i-r^{2}-2 \beta i}>0, r>0$

$\therefore D-\alpha c_{m}+\beta c_{m}>0$

$\because \theta^{M^{*}}=\frac{r(3 \alpha+\beta)\left(D-\alpha c_{m}+\beta c_{m}\right)}{8 \alpha^{2} i-3 \alpha r^{2}-8 \alpha \beta i-\beta r^{2}}>0 \therefore 8 \alpha^{2} i-3 \alpha r^{2}-8 \alpha \beta i-\beta r^{2}>0$

$\because 2 \alpha^{2} i-2 \beta^{2} i-\alpha r^{2}-\beta r^{2}>0, \alpha>\beta \therefore 2 \alpha^{2} i-2 \beta^{2} i-2 \beta r^{2}>0$

$\therefore 10 \alpha^{2} i-8 \alpha \beta i-3 \alpha r^{2}-2 \beta^{2} i-3 \beta r^{2}=\left(8 \alpha^{2} i-3 \alpha r^{2}-8 \alpha \beta i-\beta r^{2}\right)+\left(2 \alpha^{2} i-2 \beta^{2} i-2 \beta r^{2}\right)>0$

$\because \theta^{B^{*}}=\frac{r\left(D-\alpha c_{m}+\beta c_{m}\right)\left(10 \alpha^{2} i-8 \alpha \beta i-3 \alpha r^{2}-2 \beta^{2} i-3 \beta r^{2}\right)}{3 B}>0$

$\therefore B>0$

$\therefore \theta^{*}-\theta^{B^{*}}=\frac{2 r i(\alpha-\beta)^{2}\left(D-\alpha c_{m}+\beta c_{m}\right)}{3 B}>0$, i.e., $\theta^{*}>\theta^{B^{*}}$

Similarly, $\theta^{B^{*}}>\theta^{R^{*}}$ and $\theta^{R^{*}}>\theta^{M^{*}}$.

Proof of Corollary 2. $\because \alpha>\beta \therefore r^{2}+2 \alpha i-2 \beta i>0$

$\therefore \frac{\partial \theta^{*}}{\partial r}=\frac{\left(r^{2}+2 \alpha i-2 \beta i\right)\left(D-\alpha c_{m}+\beta c_{m}\right)}{\left(r^{2}-2 \alpha i+2 \beta i\right)^{2}}>0$

Similarly, $\frac{\partial \theta^{M^{*}}}{\partial r}>0, \frac{\partial \theta^{R^{*}}}{\partial r}>0, \frac{\partial \theta^{B^{*}}}{\partial r}>0, \frac{\partial \theta^{*}}{\partial i}<0, \frac{\partial \theta^{M^{*}}}{\partial i}<0, \frac{\partial \theta^{R^{*}}}{\partial i}<0$ and $\frac{\partial \theta^{B^{*}}}{\partial i}<0$.

Proof of Corollary 3. $\because D-\alpha c_{m}+\beta c_{m}>0, B>0,2 \alpha i-r^{2}-2 \beta i>0,8 \alpha^{2} i-3 \alpha r^{2}-8 \alpha \beta i-\beta r^{2}>0$

$\therefore p_{r}^{M *}-P_{r}^{R^{*}}=\frac{i r^{2}(\alpha-\beta)^{2}\left(D-\alpha c_{m}+\beta c_{m}\right)\left(4 \alpha i-2 r^{2}-4 \beta i\right)}{2 B\left(8 \alpha^{2} i-3 \alpha r^{2}-8 \alpha \beta i-\beta r^{2}\right)}>0$, i.e., $p_{r}^{M *}>P_{r}^{R^{*}}$

Similarly, $p_{r}^{R *}>P_{r}^{B^{*}}$ and $p_{r}^{B *}>P_{r}^{*}$

In summary, $p_{r}^{M *}>P_{r}^{R^{*}}>p_{r}^{B^{*}}>p_{r}^{*}$

We can get $w^{M^{*}}>w^{R^{*}}>w^{B^{*}}$ and $p_{d}^{*}>p_{d}^{B^{*}}>p_{d}^{R^{*}}>p_{d}^{M^{*}}$ likewise.

Proof of Corollary 4. $\because B>0$

$\therefore \pi_{m}^{B^{*}}-\pi_{m}^{R^{*}}=\frac{i^{2}(\alpha-\beta)^{2}\left(D-\alpha c_{m}+\beta c_{m}\right)^{2}}{3 B}>0$, i.e., $\pi_{m}^{B^{*}}>\pi_{m}^{R^{*}}$

Similarly, $\pi_{m}^{R^{*}}>\pi_{m}^{M^{*}}$

In summary, $\pi_{m}^{B^{*}}>\pi_{m}^{R^{*}}>\pi_{m}^{M^{*}}$

We can get $\pi_{r}^{R^{*}}>\pi_{r}^{M^{*}}>\pi_{r}^{B^{*}}$ and $\pi_{s c}^{*}>\pi_{s c}^{B^{*}}>\pi_{s c}^{R *}>\pi_{s c}^{M *}$ likewise. 
Proof of Corollary 5. $p_{d}^{*}=\frac{D i+\alpha c_{m} i-r^{2} c_{m}-\beta c_{m} i}{2 \alpha i-r^{2}-2 \beta i}$ and $p_{r}^{*}=\frac{D i+\alpha c_{m} i-r^{2} c_{m}-\beta c_{m} i}{2 \alpha i-r^{2}-2 \beta i}$

$\therefore p_{d}^{*}=p_{r}^{*}$

$\therefore D_{1}^{*}-D_{2}^{*}=(\alpha+\beta)\left(p_{d}^{*}-p_{r}^{*}\right)=0$

$\therefore D_{1}^{*}=D_{2}^{*}$

$\because 8 \alpha^{2} i-3 \alpha r^{2}-8 \alpha \beta i-\beta r^{2}>0, D-\alpha c_{m}+\beta c_{m}>0, \alpha-\beta>0, i>0$

$\therefore p_{d}^{M *}-p_{r}^{M *}=\frac{-2 i(\alpha-\beta)\left(D-\alpha c_{m}+\beta c_{m}\right)}{8 \alpha^{2} i-3 \alpha r^{2}-8 \alpha \beta i-\beta r^{2}}<0$, i.e., $p_{d}^{M *}<p_{r}^{M *}$

$\because D_{1}^{M *}-D_{2}^{M *}=(\alpha+\beta)\left(p_{d}^{M *}-p_{r}^{M *}\right)<0$

$\therefore D_{1}^{M *}<D_{2}^{M *}$

Similarly, $p_{d}^{R^{*}}<p_{r}^{R^{*}}, p_{d}^{B^{*}}<p_{r}^{B^{*}}, D_{1}^{R^{*}}<D_{2}^{R^{*}}$ and $D_{1}^{B^{*}}<D_{2}^{B^{*}}$.

\section{References}

1. Arias-Maldonado, M. The anthropocenic turn: Theorizing sustainability in a postnatural age. Sustainability 2016, 8, 10. [CrossRef]

2. Gray, N.F. What is sustainability? Sustainability 2010, 2, 3436-3448. [CrossRef]

3. Linton, J.D.; Klassen, R.; Jayaraman, V. Sustainable supply chains: an introduction. J. Oper. Manag. 2007, 25, 1075-1082. [CrossRef]

4. Tippayawong, K.; Niyomyat, N.; Sopadang, A.; Ramingwong, S. Factors affecting green supply chain operational performance of the thai auto parts industry. Sustainability 2016, 8, 1161. [CrossRef]

5. Sarkis, J.; Zhu, Q.; Lai, K.H. An organizational theoretic review of green supply chain management literature. Int. J. Prod. Econ. 2011, 130, 1-15. [CrossRef]

6. Fahimnia, B.; Sarkis, J.; Davarzani, H. Green supply chain management: A review and bibliometric analysis. Int. J. Prod. Econ. 2015, 162, 101-114. [CrossRef]

7. Kim, D.; Kim, S. Sustainable Supply Chain Based on News Articles and Sustainability Reports: Text Mining with Leximancer and DICTION. Sustainability 2017, 9, 1008. [CrossRef]

8. Corbett, C.J.; Decroix, G.A. Shared-savings contracts for indirect materials in supply chains: Channel profits and environmental impacts. Manag. Sci. 2001, 47, 881-893. [CrossRef]

9. Esfahbodi, A.; Zhang, Y.; Watson, G. Sustainable supply chain management in emerging economies: Trade-offs between environmental and cost performance. Int. J. Prod. Econ. 2016, 181, 350-366. [CrossRef]

10. Zhu, W.; He, Y. Green product design in supply chains under competition. Eur. J. Oper. Res. 2017, 258, 165-180. [CrossRef]

11. Lin, C.T.; Chang, Y.H.; Mi, C. Develop eco-friendly enterprise: Aligning enablers with strategy. Sustainability 2017, 9, 570. [CrossRef]

12. Jamali, M.B.; Rasti-Barzoki, M. A game theoretic approach for green and non-green product pricing in chain-to-chain competitive sustainable and regular dual-channel supply chains. J. Clean. Prod. 2018, 170, 1029-1043. [CrossRef]

13. Joshi, Y.; Rahman, Z. Factors affecting green purchase behaviour and future research directions. Int. Strateg. Manag. Rev. 2015, 3, 128-143. [CrossRef]

14. Syaekhoni, M.A.; Alfian, G.; Kwon, Y.S. Customer purchasing behavior analysis as alternatives for supporting in-store green marketing decision-making. Sustainability 2017, 9, 2008. [CrossRef]

15. Hua, G.; Wang, S.; Chengc, T.C.E. Price and lead time decisions in dual-channel supply chains. Eur. J. Oper. Res. 2010, 205, 113-126. [CrossRef]

16. Chen, J.; Zhang, H.; Sun, Y. Implementing coordination contracts in a manufacturer stackelberg dual-channel supply chain. Omega 2012, 40, 571-583. [CrossRef]

17. Lazzarini, S.; Chaddad, F; Cook, M. Integrating supply chain and network analyses: the study of netchains. J. Chain Netw. Sci. 2001, 1, 7-22. [CrossRef]

18. Srivastava, S.K. Green supply-chain management: a state-of-the-art literature review. Int. J. Manag. Rev. 2007, 9, 53-80. [CrossRef]

19. Diabat, A.; Govindan, K. An analysis of the drivers affecting the implementation of green supply chain management. Resour. Conserv. Recycl. 2011, 55, 659-667. [CrossRef] 
20. Zhu, Q.; Sarkis, J.; Lai, K.H. Confirmation of a measurement model for green supply chain management practices implementation. Int. J. Prod. Econ. 2008, 111, 261-273. [CrossRef]

21. Ashby, A.; Leat, M.; Hudson-Smith, M. Making connections: a review of supply chain management and sustainability literature. Supply Chain Manag. 2012, 17, 497-516. [CrossRef]

22. Seuring, S.; Müller, M. From a literature review to a conceptual framework for sustainable supply chain management. J. Clean. Prod. 2008, 16, 1699-1710. [CrossRef]

23. Oliveira, U.R.D.; Espindola, L.S.; Silva, I.R.D.; Silva, I.N.D.; Rocha, H.M. A systematic literature review on green supply chain management: Research implications and future perspectives. J. Clean. Prod. 2018, 187, 537-561. [CrossRef]

24. Bojarski, A.D.; Laínez, J.M.; Espuña, A.; Puigjaner, L. Incorporating environmental impacts and regulations in a holistic supply chains modeling: An lca approach. Comput. Chem. Eng. 2009, 33, 1747-1759. [CrossRef]

25. Barari, S.; Agarwal, G.; Zhang, W.J.; Mahanty, B.; Tiwari, M.K. A decision framework for the analysis of green supply chain contracts: An evolutionary game approach. Expert Syst. Appl. 2012, 39, 2965-2976. [CrossRef]

26. Sheu, J.B.; Chen, Y.J. Impact of government financial intervention on competition among green supply chains. Int. J. Prod. Econ. 2012, 138, 201-213. [CrossRef]

27. Chen, S.; Wang, X.; Wu, Y.; Ni, L. Pricing policies in green supply chains with vertical and horizontal competition. Sustainability 2017, 9, 2359. [CrossRef]

28. Ghosh, D.; Shah, J.A. A comparative analysis of greening policies across supply chain structures. Int. J. Prod. Econ. 2012, 135, 568-583. [CrossRef]

29. Dai, R.; Zhang, J.; Tang, W. Cartelization or cost-sharing? comparison of cooperation modes in a green supply chain. J. Clean. Prod. 2017, 156, 159-173. [CrossRef]

30. Yang, D.; Xiao, T. Pricing and green level decisions of a green supply chain with governmental interventions under fuzzy uncertainties. J. Clean. Prod. 2017, 149, 1174-1187. [CrossRef]

31. Wei, J.; Wang, W.; Tsai , S.; Yang, X. To Cooperate or Not? An Analysis of Complementary Product Pricing in Green Supply Chain. Sustainability 2018, 10, 1392. [CrossRef]

(C) 2018 by the authors. Licensee MDPI, Basel, Switzerland. This article is an open access article distributed under the terms and conditions of the Creative Commons Attribution (CC BY) license (http:/ / creativecommons.org/licenses/by/4.0/). 